\title{
Neighborhood Social Change and Perceptions of Environmental Degradation
}

\author{
Jennifer S. Barber \\ Ann E. Biddlecom \\ William G. Axinn \\ University of Michigan
}

\begin{abstract}
This paper investigates how changes in neighborhood facilities-new schools, health posts, bus services, mills, dairies, agricultural cooperatives, and other facilities-influence perceptions of environmental degradation. We use three types of data from a rural area in Nepal: (1) data on changing neighborhood facilities from 171 neighborhoods, collected using ethnographic, survey, and archival methods; (2) survey data on household characteristics and environmental perceptions from 1,651 households; and (3) individual-level survey data. We find that new neighborhood facilities are associated with perceptions of environmental degradation. This is important because perceptions may indicate objective environmental degradation, encourage participation in programs to improve the environmental, and influence environmental behavior.
\end{abstract}

KEY WORDS: social change; environmental degradation; perceptions; Nepal; neighborhood.

\section{INTRODUCTION}

In a rural setting primarily devoted to subsistence agriculture, social changes-such as improved access to schools, employers, clinics, bus stops, agricultural production centers, and markets-can have a dramatic influence on the daily lives of residents. Studies have documented the influence

Please address correspondence to Jennifer S. Barber, Institute for Social Research, University of Michigan, 426 Thompson Street, Ann Arbor, Michigan, 48106-1248; e-mail: jebarber@ umich.edu. 
of these sorts of social changes on individuals in a broad range of substantive areas, including demography, gender relations, child development, criminology, and education (Axinn \& Yabiku, 2001; Brooks-Gunn et al., 1993; Entwisle \& Mason, 1985; Huber, 1991; Raudenbush, 1988; Rountree et al., 1994). In many poor countries, a growth in facilities signals a fundamental improvement in the quality of daily life: more stable food supplies, sewage systems, and clean drinking water; a larger selection of many other goods and services; and decreased infant, maternal, and old age mortality. In recent years, however, environmental and social scientists have become concerned that some of these changes might also lead to environmental degradation (Bongaarts, 1996; Cohen, 1995; Eckholm, 1976; Ehrlich, Ehrlich \& Daily, 1993; Heilig, 1997; Myers, 1991; Rees, 1996). For example, new government-run agricultural cooperatives that sell subsidized chemical fertilizers and pesticides have the potential to improve crop production, but may also pollute groundwater sources or leach nutrients from the soil, resulting in long-term soil degradation.

The particular focus of this study is on local residents' perceptions of environmental degradation over the past three years. People's perceptions of environmental degradation are important to understand for several reasons. First, perceptions of environmental degradation may serve as useful indicators of objective environmental degradation when objective data are not available. Second, perceptions influence grassroots participation in programs and policies aimed at improving environmental conditions, one of the key components of making any program sustainable (Daniere \& Takahashi, 1999). Third, perceptions of environmental degradation influence individuals' environmental behaviors. For example, if soil fertility is not perceived as a problem by farmers, then they are not motivated to change their farming practices to mitigate or slow declines in soil fertility.

The purpose of this research is to document the influence of a set of social changes on perceptions of local environmental degradation. A great deal of research on the environment in poor countries focuses at high levels of aggregation (e.g., province or country-level). Less empirical research on poor countries focuses on environmental degradation at more local levels, such as communities or neighborhoods in which individuals spend most of their daily life (National Research Council, 1993). This paper focuses on the very local context-neighborhoods of five to fifteen households-because this local context is likely to be most directly linked to individuals' daily lives and decision making. We also focus on a specific set of social changes: the introduction of nearby schools, employers, clinics, bus stops, markets, banks, grain mills, agricultural cooperatives, dairies, and police stations (see descriptions under "Setting" below). 
J. S. BARBER, A. E. BIDDLECOM, AND W. G. AXINN

\section{SETTING}

We examine the relationship between the introduction of new neighborhood facilities and perceptions of environmental degradation in a district of south-central Nepal. Chitwan district is a wide flat valley nestled in the Himalayan foothills at approximately 450 feet above sea level. Nepalese census data indicate that in 1981 Chitwan had 259,571 residents, and by 1991 (the most recent census data available) that number had increased to 354,488 (Gurung, 1998). This constitutes a 37 percent increase, or an annual growth rate of 3.12 percent-a slightly higher annual growth rate relative to other districts in Nepal during that period. Population growth in this area has resulted from both high fertility rates and high rates of inmigration. Population density in 1991 was approximately 414 people per square mile (Gurung, 1998). Although more recent census data are not available, if the growth rates remained at 3.12 percent between 1991 and 2001, the population in 2001 would be 484,092 and population density would be 565 people per square mile. ${ }^{1}$ Given that much of the land in Nepal is uninhabitable because of steep mountainside slopes, 565 is a relatively high population density. We analyze a 100-square mile area of this district, the Western Chitwan Valley. Figure 1 shows the location of Chitwan district within Nepal, and the location of the study area within the district. This rural area in Nepal provides an ideal setting for investigating the potential links between social change and perceptions of environmental degradation for three reasons.

First, Nepal is one of the poorest countries in the world, and is experiencing very rapid social change. The per capita Gross Domestic Product (GDP) for Nepal in 1992 was US\$144 (relative to $\$ 23,332$ in the United States) (United Nations, 1995). Only 13 countries have a lower estimated GDP, such as the Asian countries of Cambodia (US\$105) and Vietnam (US\$131) (United Nations, 1995). Life expectancy in Nepal is estimated at 57 years for women and 58 years for men, and over 80 of every 1,000 liveborn infants die within the first year of life (United Nations, 2000). In 1996, the majority of Nepalese men and women were illiterate (59 percent of men and 89 percent of women) (United Nations, 2000).

However, Nepal has experienced relatively rapid social change in recent years. Chitwan, in addition to Kathmandu (the capital and largest city of Nepal), has been at the center of much of this change (Shivakoti et al., 1999). Until the early 1950s, Chitwan Valley was covered by virgin forests infested with malaria-carrying mosquitos and home to many dangerous fauna, ranging from poisonous snakes to Bengal Tigers. Beginning in the mid-1950s, the government began to clear the forest, eradicate malaria, 


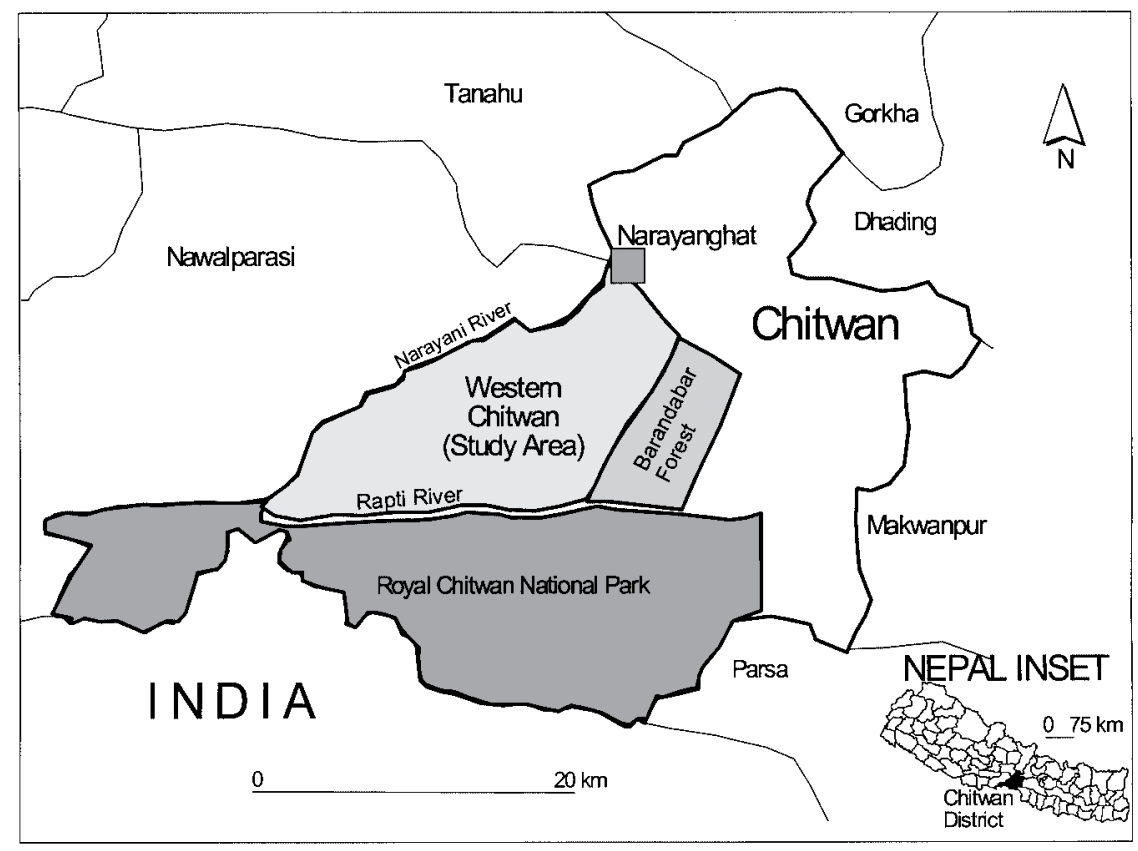

FIGURE 1. Map of study area.

and make farm plots available to in-migrants. Approximately one-third of the original forest was preserved as Chitwan National Park, which remains home to several endangered species today (Shivakoti et al., 1999).

Rich soils, flat terrain, and the promise of new opportunities drew many farmers into the area, but the valley remained a remote, isolated frontier until the 1970s. The first year-round road into Chitwan was completed in 1979, linking Narayanghat, Chitwan's largest town, to cities in Eastern Nepal and India (Axinn \& Axinn, 1983). Other important roads followed, linking Narayanghat to Kathmandu, Nepal's capital city. Because of Narayanghat's central location, this once isolated town was transformed into the transportation hub of the country by the mid-1980s (Shivakoti et al., 1999). This change produced a rapid proliferation of government services, businesses, and wage labor jobs in Narayanghat that spread throughout Chitwan (Axinn \& Yabiku, 2001; Pokharel \& Shivakoti, 1986), dramatically altering the social organization of the district. Bus service through the valley has given residents access to the wage labor opportunities and commerce of Narayanghat. Commercial enterprises, such as grain mills and new retail outlets, 
have scattered throughout Chitwan. Government services-from schools, to agricultural cooperatives (which sell subsidized chemical fertilizer and pesticides), to police stations - have also sprung up (Axinn \& Barber, 2001; Axinn \& Yabiku, 2001). These social changes constitute a significant transformation of the local context for the hundreds of small farming communities in Western Chitwan Valley, a transformation experienced firsthand by many of the current adult residents (Axinn \& Yabiku, 2001).

Figure 2 presents the history of change over time in some of the neighborhood facilities of Western Chitwan Valley. The lines represent the average time in minutes (for all 171 neighborhoods) required to walk to the nearest bus stop, school, dairy, mill, and agricultural cooperative (co-op) for each of the years from 1953 to 1995 . The declining slope of these lines indicates that the average time to reach each of these services has declined dramatically.

We also re-calculated measures of temporal change in different metrics, including the number of services available each year, years of exposure to each service within a fixed radius, and the most common temporal sequence of these services within a fixed radius. Each of these analyses demonstrates the same information as Figure 2-although these neighbor-

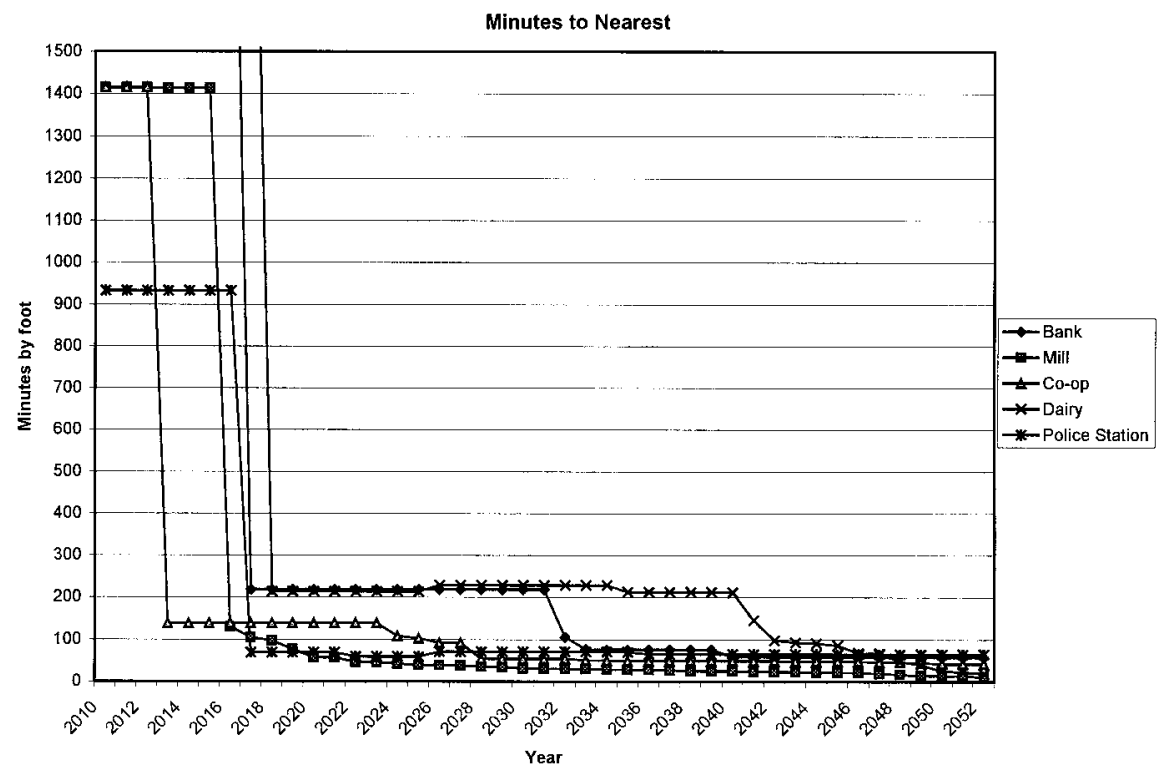

FIGURE 2. History of change in neighborhood facilities of Western Chitwan Valley. 
hood changes tend to occur together, making it difficult to ascertain which specific type of facility affects perceptions of environmental degradation, the main point is that the spread of neighborhood facilities throughout the valley has been dramatic.

A second reason that Nepal is an ideal setting for studying the link between environmental degradation and social change is that it contains an extremely diverse array of flora and fauna, including multiple species endemic to the region (not found elsewhere). In fact, the lower slopes of the Himalayas, including a part of eastern Nepal, have been identified as an environmental "hot spot," a region of the world that is rich in endemic species and is also environmentally threatened (Myers, 1988). This makes the region particularly important to continuing biodiversity (Chaudhary, 1998; Zurick \& Karan, 1999). Nepal's flora and fauna range from nearly 2,000 species of fungi and 1,000 species of algae, to approximately 100 species of reptiles, over 800 species of birds, nearly 3,000 species of butterflies and moths, and 181 species of mammals including the Bengal tiger and the one-horned rhinoceros (Chaudhary, 1998).

The specific setting for our research borders the Royal Chitwan National Park and a National Forest called Barandabar Forest-both government preserves for flora and fauna species. Greater understanding of the influence of social change on environmental degradation in this region will thus provide important information for conservation efforts in both this and similar regions.

The third reason that Nepal is an ideal study setting is that its economy is based mainly on subsistence agriculture. Rapid population growth in the relatively recent past has stimulated the Nepalese government to focus on improving agriculture in the region, including making heavy investments in irrigation, mechanization, improved seeds, pesticides, fertilizers, and new methods of production and marketing (Shivakoti \& Pokharel, 1989). Many of these investments have occurred in Chitwan, where the country's premier agricultural university is located. Investigation of the relationship between social change and perceptions of environmental degradation in this setting will provide insights for promoting environmental quality in regions experiencing rapid change in agricultural practices. Such regions often border areas of extreme biodiversity and these changes in agricultural practices can have significant consequences for efforts to conserve biodiversity.

\section{SOME IMPORTANT ASPECTS OF THE ENVIRONMENT IN NEPAL}

We focus on aspects of the environment that are salient to the study population in rural Nepal, who are primarily involved in subsistence agri- 
culture and use animal husbandry to supplement their diets with milk and meat. Three dimensions of environmental quality are most likely to affect the daily lives of the local residents and the biodiversity in and around their neighborhoods: availability of common grazing and forest land, degree of soil fertility, and quality of water. Other South Asian environmental research has focused on these same dimensions (e.g., Agarwal, 1992). Below, we describe how each of these aspects of the environment plays a crucial role in the lives of our study population.

\section{Common Grazing and Forest Lands}

Common grazing and forest lands are a critical resource in Nepal, as they are in other parts of South Asia (Agarwal, 1992), especially for poor farmers who do not own enough land to set aside plots for grazing their animals. In our representative sample of neighborhoods in Western Chitwan Valley, the average neighborhood size is 697,839 square feet $(.03$ square miles), with an average of 11,654 square feet of common land (including grazing, forest, and plantation lands). Virtually every farmer in Chitwan has several animals (Axinn \& Axinn, 1983; Shivakoti et al., 1999); approximately 77 percent of sample households were engaged in raising livestock of some sort-bullocks, cows, buffalo, sheep, goats, or pigs. Female water buffaloes are the most common livestock, with 57 percent of households owning at least one. Common grazing and/or forest land are farmers' preferred ways to feed their animal herds - this is the only way to feed animals without having to purchase fodder or send household members to collect fodder from common lands. However, only 22 percent of households in our sample are able to feed their animals at least partly by grazing. Of those households who graze their animals, 39 percent graze mainly on common forest land, and 27 percent on common grazing land.

Common forest lands are also crucial because they are a source of free fodder (mostly small branches and leaves), as only 6 percent of households reported feeding their animals on grazing alone. Among households who relied at least partially on collecting fodder to feed their animals, only 2 percent reported purchasing all of their fodder. The other 98 percent of households relied on their own cultivated land or common land to collect fodder. Furthermore, the location and accessibility of these common lands is critical-respondents reported an average time of 106 minutes to travel to the place where the fodder is, collect it, and then bring it home. Nearly all of the households (99 percent) indicated that they walked to get the fodder, and the average household sent at least one man, one woman, and one child to collect fodder. Fodder collection thus represents a fairly large and time-consuming task for these households. 
Common forest lands are important for another reason: they are the main place people collect wood for fuel without having to purchase it. Of the 92 percent of the sample households that reported using wood for fuel in their homes, 19 percent purchased all of the firewood they used, 81 percent collected at least some of it, and 49 percent collected all of it. In the lowlands of Nepal (such as Chitwan), the United Nations estimates that 84 percent of households' energy use comes from firewood, and between 1.1 and 2.5 hours per day are spent collecting firewood (United Nations, 1995). Respondents in this study area indicated an even larger amount of time spent collecting firewood-5 hours and 37 minutes daily. This work is primarily done by women and children.

Common forest lands are located along most of the borders of the study site; there are small forested areas throughout the study area, as well as two large forest preserves: The Royal Chitwan National Park borders the southern part of the study site, the Barandabar Forest borders the east (see Figure 2). Both of these forests are protected-the National Park by armed guards, and the Barandabar Forest by a large fence. However, residents sometimes enter (legally during two weeks of the year, illegally during other times) the National Park to gather fodder or firewood, especially if nearby plots have been depleted or destroyed. The Narayani River is the northwestern border, and the river contains islands of forest land. Although the river is too wide to swim across, residents can and do swim or paddle by boat to the forest land in the middle of the river, often with their cows swimming alongside.

\section{Soil Fertility}

The vast majority of households in Western Chitwan Valley are engaged in some type of farming. In 1996, for example, over 80 percent of households in Chitwan farmed. Most are subsistence farmers-few households produce more than enough food to feed all household members. Farmers in this setting grow a three-crop rotation, including as much rice as possible. On the low-lying and more valuable khet land, farmers usually grow two crops of rice and one of corn. On higher bari land, only one crop of rice can be grown-during the monsoon season-and the other two crops are usually corn and wheat. Occasionally farmers grow mustard (for oil production) or buckwheat, as well. The average farm size is small: .94 acre of bari land and 1.84 acres of khet land. Farms are also highly fragmented, with only 38 percent of farming households farming one contiguous piece of land and 13 percent farming 4 or more separate plots. In addition, only 1 percent of households own a tractor, and only 14 percent own 
any other farm implement such as a corn sheller, chaff cutter, sprayer, or thresher.

Given the small, fragmented, and labor-intensive nature of farming in Chitwan, subsistence farming is a very difficult job with little margin for failure. Any decrease in crop outputs (due to soil infertility, erosion, pestilence, etc.) could pose a serious threat to a household's livelihood. To help reduce their risks, some farmers use agricultural chemicals. In the study site, 83 percent of those who farmed reported recently using chemical fertilizers and 23 percent reported using pesticides.

\section{Water Table}

Safe drinking water and the large amounts of water necessary for irrigating crops are scarce in many countries throughout Asia (United Nations, 1995, p. 49). Nepal is no exception. Only 54 percent of the households in Chitwan reported a private source of drinking water, such as a tap or well; the others relied on neighborhood water sources, their neighbors' tap or well, common sources outside their neighborhood, or natural sources such as streams or rivers. Of those households with private drinking water sources, most were tube wells (82 percent); however, in a sample of public neighborhood water sources, only 59 percent were tube wells. Furthermore, these tube wells varied substantially in depth, with an average of approximately 14 feet below the surface. As noted by Agarwal (1992), tube wells are mainly owned by relatively rich people, and groundwater levels have fallen in many regions throughout India due to the "indiscriminate sinking of tube wells-the leading input in the Green Revolution technology" (Agarwal, 1992, p. 130). Agarwal refers to tube wells as a major factor in the unequal distribution of the "underground commons" (the water table)

(Agarwal, 1992, p. 133). The majority of other public neighborhood water sources in the sample neighborhoods were shallow wells, most of which were open wells, thus increasing opportunities for parasites and other disease-causing agents to enter the source of drinking water.

\section{THEORETICAL FRAMEWORK}

Although our data do not contain the information to test most of the mechanisms that may link the presence of new neighborhood facilities, our indicator of social change, to perceptions of environmental degradation, we delineate these mechanisms to explain why we think the link is likely. First, because actual environmental degradation is probably an important 
determinant of individuals' perceptions of environmental degradation, we focus on mechanisms that might link social change to actual environmental degradation. Second, because other factors (in addition to actual environmental degradation) are likely to influence individuals' perceptions of environmental degradation, we also focus on mechanisms that may link social change to perceptions of environmental degradation that may operate regardless of whether actual environmental degradation occurs. Our general framework draws from the "family mode of social organization" perspective for studying social change (Ogburn and Nimkoff, [1955] 1976; Thornton \& Fricke, 1987; Thornton \& Lin, 1994); the "feminist environmentalism" perspective for exploring the interrelationships between gender, class, and environmental degradation developed by Bina Agarwal (1992, 1997); and Marx's concept of metabolic rift linking social change to environmental consequences (Marx, [1867] 1976).

\section{Relationships Between Social Change and Actual Environmental Degradation}

We posit three types of mechanisms that link the presence of new neighborhood facilities to actual environmental degradation: changes in land use (statization and privatization of lands formerly held in common), population growth (fueled by in-migration toward public and private services), and metabolic rift (Axinn et al., 2000; Foster, 1999; Marx, [1867] 1976).

Changes in Land Use. Changes in land use may degrade the neighborhood environment. A new neighborhood facility occupies land that may have been previously common land used for grazing and firewood/fodder collection, or private land used for agricultural purposes. Working in the same region, Shivakoti et al. (1999) showed that the area of common land declines as the number of facilities increases.

Statization. Common lands are often the only land available for new public facilities, such as schools, health centers, bus stops, dairies (milk collection points established by the government), agricultural cooperatives (government-established centers that sell subsidized chemical fertilizers and pesticides), and police stations. The expense of purchasing privately owned land may be a substantial obstacle to the establishment of new public facilities. Thus, neighborhoods are often faced with the choice of foregoing new facilities or giving up common land to have them. Neighborhoods in this setting are relatively small in area, averaging about 16 acres (about 
$835 \times 835$ feet) in area with a little more than a quarter acre of common land (including grazing, forest, and plantation lands). Thus, a new public facility or road has the potential to substantially reduce local land use. Other research in this setting shows, for example, that each additional minute to the nearest school is associated with 20 percent more common land in the neighborhood (Shivakoti et al., 1999). In other words, neighborhoods located further from schools have substantially more common land.

It is important to note that the neighborhood leaders who decide whether to trade common land for public facilities may not be the residents most negatively affected by these decisions. According to research in South Asia (e.g. Agarwal, 1992, 1997), and our own ethnographic observations, the poorest residents are much less able to take advantage of public services (e.g., send their children to school or to the doctor, produce enough surplus milk to sell to the collection station) than their richer neighbors, and are also more likely to rely on the common lands.

Privatization. The expansion of business and commerce may also have direct effects on land use, but here the influence is more likely to be concentrated on conversion of agricultural land into land covered by buildings. Local residents are less likely to tolerate the placement of new commercial facilities on common lands, especially because these enterprises are expected to generate profits, thereby providing entrepreneurs the means to purchase privately held lands. In this setting, farmers are often economically forced to sell a portion of their land to private business enterprises, especially when a natural disaster (e.g., floods, landslides, pests) or a particularly difficult growing season has led to poor crop yields. As mainly subsistence farmers, they may choose to sell their land for cash they can use to feed their family in the short run at the expense of growing more food in the long run. Thus, farmers may be forced to rely on smaller plots of land. This may lead to overcropping. For example, population increases as well as the development of new commercial facilities may necessitate the cultivation of new, lower quality land that was not previously farmed. This land may require more fertilizer to cultivate and would account for the increasing use of fertilizer by farmers. If no new land is available, this may force farmers to grow additional crops on their existing land. Both of these processes may decrease overall soil fertility. Using poor quality or overcropped land means farming less fertile soil, which can lead to lower crop production. To counteract this, farmers often apply chemical fertilizers, which tend to have declining efficiency and are thus required in greater quantities each subsequent year to achieve the same yield.

Reduced soil fertility and the associated increase in chemical fertiliz- 
ers decrease the amount of water that soil can hold and leads to increased soil erosion. Less water absorbency necessitates more frequent irrigation, which may deplete ground water reserves. Also, the erosion associated with decreased soil fertility reduces the efficacy of surface water reservoirs, which means that irrigation may require pumping out even more ground water. Water reserves may also be reduced or depleted if new commercial facilities sink more tube wells. This is likely to be felt most by poorer residents, who are often forced to rely on shallower wells and surface sources for their water.

Population Growth. Population growth is another mechanism by which new facilities can be linked to environmental degradation. Overall, it is likely that the local development of neighborhood facilities such as health centers, shops, agricultural production centers, and schools stimulates higher levels of in-migration of new residents from other areas and lower levels of out-migration, producing a more densely settled local area. However, according to the development and migration literature, it is not clear whether in-migration results from new neighborhood facilities (e.g., Baydar et al., 1990; Dang, Goldstein, \& McNally, 1997; Martin, 1992).

If population growth accompanies the arrival of neighborhood facilities, then water, land, and air quality may deteriorate from human waste, contamination, and garbage if related improvements in infrastructure (such as sewage systems or drinking water supplies) do not accompany the population growth. The literature on the link between population growth and environmental deterioration is mixed. Some scholars argue that the connection is weak at best (e.g., Billsborow \& DeLargy, 1990).

If population growth results from new neighborhood facilities, this population growth may also affect land use. As more people move into an area, the amount of land available for cultivation is reduced. This forces the intensification of already cultivated areas or the extensification of cultivation into marginal areas that otherwise would remain fallow or unused. In-migrants often purchase land from farmers. Other in-migrants may be particularly poor-forced from their homes by severe environmental degradation (e.g., one neighborhood in our study area no longer exists because it eroded into the river) or natural disasters. These poor in-migrants are likely to become what Nepalese people call sukumbasi, or squatters, with crudely built homes on common lands. Thus, both privately held lands and publicly held lands are likely to be affected by population growth.

Metabolic Rift. We posit a third mechanism that links new neighborhood facilities to environmental degradation. It is based on Marx's idea of 
the metabolic rift: that the spread of the capitalist mode of production results in humans interacting less directly with the natural environment from which they derive their sustenance, which in turn leads to its exploitation (Foster, 1999; Marx, [1867] 1976, [1863-65] 1981). This idea predicts that as new public and private services and facilities (such as grain mills, milk collection stations, and employment opportunities) spread throughout communities, individuals will alter their agricultural practices and interact less directly with their environment. This lack of interaction reduces individuals' tendency to act in the best interests of the environment. For example, as family members take wage labor jobs, households may switch to purchasing (with their wages) some or all of the firewood they need, rather than gathering the wood themselves. This separation from the means and sources of wood collection may inure residents to the long-term consequences of deforestation by those supplying the wood.

Both Marx and Engels predicted that shifts toward capitalist modes of production would lead to degradation of the natural environment in terms of soil fertility, water, and other natural resources (Foster, 1999). Negative consequences for the environment are likely because individual and household consumption decisions are based on decreasing knowledge of the environmental consequences of those decisions.

Using the "family modes of social organization" perspective, we broaden this idea from a focus on modes of production to modes of social organization (Ogburn \& Nimkoff, [1955] 1976; Thornton \& Fricke, 1987; Thornton \& Lin, 1994). Nepal, like most societies, was dominated by family modes of social organization at one time (Thornton \& Fricke, 1987). In other words, in the past the vast majority of individuals' needs were taken care of by their families-including consumption, production, recreation, socialization, protection, and residence. There were no markets to provide food and other items, no schools to educate and socialize children, no movie theaters for recreation, no police force for protection. The dramatic spread of nonfamily facilities in Western Chitwan Valley-as described above and illustrated in Figure 1-reorganized much of social life outside the family. Here we look at the effect of this change in mode of social organization on environmental connectivity, positing that the greater the intensity of nonfamily social organization, the more distant humans' interactions become from their natural environment (Axinn, Barber, \& Biddlecom, 2000).

Metabolic rift is also related to what Agarwal terms the "erosion of community resource management systems" in many areas (Agarwal, 1997, p. 25, 1992, p. 133). In Nepal, agricultural groups called "users' groups" are often formed for the cooperative management of a common natural resource such as a forest, irrigation system, or common land (Barber et al., 
2002). Users' groups, comprised of local residents who make use of a common resource, create rules and guidelines for the development, utilization, and conservation of the resource (Joshi, Jali, \& Hamid, 1997), and manage conflicts among users (Thapa, 1997). By joining forces, members are able to optimize overall use of the resource while allowing each user to share in its benefits. In addition, a users' group may register with formal organizations or agencies that contribute financial or legal support (Shukla, Shivakoti, Benjamin, \& Ostrom, 1997). Agarwal $(1992,1997)$ contends that the statization and privatization of communal resources - which in our study area have accompanied the spread of facilities and services-undermine this type of local resource management system. As individuals are less directly involved in the transformation of natural resources for consumption needs, organized local management of natural resources is likely to become less effective, and further environmental degradation may continue.

\section{Relationships Between Social Change and Perceptions of Environmental Degradation}

Many factors are likely to influence whether individuals perceive environmental degradation. First, as described, personal experience of actual environmental degradation is likely to be an important factor. When the environment actually deteriorates, individuals and households are probably more likely to perceive environmental degradation relative to residents of areas where the environment has improved or stayed the same.

Second, the extent to which individuals interact with the environment is likely to influence their perceptions of environmental degradation. This is consistent with Marx's theory of metabolic rift (Foster, 1999; Marx, [1867] 1976), and suggests that some groups in our study are more likely than others to perceive environmental degradation because of its effects on their environment-related activities, regardless of the degree of actual environmental degradation. For example, men in this setting, who are the household members typically responsible for buying chemical fertilizers, may be more likely than women to perceive reduced soil fertility because their fertilizer expenses have grown. On the other hand, women and children, who are most often responsible for collecting firewood and water, may be more likely to perceive depleted wood and water resources because their collection times have increased. Finally, impoverished and/or landless people may be most likely to perceive the degradation and depletion of resources such as common grazing and forest lands or the water table, but 
may be less likely to perceive changes such as increasing fertilizer requirements.

Third, some research suggests that the mere presence of public and private facilities near individuals' neighborhoods can have a direct influence on their attitudes. One study found that respondents who lived near a school-regardless of whether they or their neighbors were actually able to attend the school-had more positive attitudes toward independence from parents (Barber, in press). This is consistent with social psychological research on "mere exposure" (Zajonc, 1968). Although attitudes toward independence from parents are probably not directly related to perceptions of environmental degradation, these perceptions may be similarly affected by the mere presence of new neighborhood facilities. For example, if residents associate social changes such as new neighborhood facilities with environmental degradation, their presence may cause local residents to worry about environmental degradation. If this is true, then residents of neighborhoods with new facilities may be more likely to perceive environmental degradation than residents of other neighborhoods that are further from these services.

\section{HYPOTHESES}

We test five specific hypotheses related to our overall expectation that increasing numbers of neighborhood facilities in the study area are likely to lead to perceived environmental degradation. We hypothesize that, as the number of neighborhood facilities increases:

1. respondents in households that stall-feed their animals will report having to travel further for fodder;

2. respondents in households that collect fuel wood will report having to travel further for the wood;

3. respondents in households that farm using fertilizers will report having to apply increasing amounts of chemical fertilizers to achieve the same crop yield; and

4. respondents will report a lowering of the local water table.

In addition, we test whether the relationship between increasing neighborhood facilities and perceptions of environmental degradation is due, in part, to household characteristics such as household size, housing quality, land ownership, and resource consumption. 


\section{DATA}

The data used in these analyses come from three sources. First, we draw on neighborhood-level data for a representative sample of 171 neighborhoods in Western Chitwan Valley. Neighborhoods (called tol in Nepalese) are set up as clusters of houses surrounded by farmland. The housing area usually includes a common water source where women congregate to collect water for drinking and cooking, to wash themselves and their children, and to wash dishes after meals. Common neighborhood land is used for grazing livestock and collecting fodder, collecting water to irrigate crops, and collecting fuel wood for cooking. Although neighborhoods are not necessarily kinship-based, neighbors know one another quite well. The common areas in these communities, especially during particular times of day, are central areas for gossip, sharing stories, and general congregation.

These data were collected in 1994 using the Neighborhood History Calendar method (Axinn et al., 1997). This data collection procedure included some structure; however, not as much structure as many standardized individual-level survey interviews-interviewers were not required to ask questions exactly as worded or follow the sequence of questions. This flexibility in the interviewing process allowed the interview to take on a more natural character that helps the respondent to provide more accurate and detailed information. The data collection also followed a multipleinterview format. In each neighborhood interviewers collected contextual data from at least two different sources, and they often consulted three or four. Further, each of these interviews was not constrained to be an individual interview, and group interviews were common. These group interview situations paralleled the Participatory Rural Appraisal technique, encouraging the assembled neighborhood residents to correct each other and come to some collective agreement about the dates of important neighborhood changes (Chambers, 1985). Even when these group interviews were used, they were counted as one source and interviewers were required to collect at least one more group interview about the same neighborhood information before completing the neighborhood. We also cross-checked information provided by neighborhood residents against archival sources whenever possible. In fact this was often possible, and most dates of changes like new schools, health services, electrification, and bus services were crosschecked against archival sources. The resulting neighborhood data include information about all new facilities in the neighborhoods over a period of 50 years, such as new schools, health centers, and bus routes.

Second, we use household data collected from every household in these 171 neighborhoods using a structured survey completed in 1996. Any house- 
hold member was allowed to act as an informant, and multiple household members were encouraged to participate in the interview. More than onethird of the household interviews involved multiple respondents, and about $5 \%$ involved three or more respondents. Approximately one-half of the primary respondents was female, and the average age of the primary respondent was 42. The survey response rate was 100 percent. The household measures we use include the main household informant's perceptions of environmental degradation over the past three years, as well as a variety of household-level measures of demographic characteristics, housing quality, and ownership of consumer goods and land.

Third, we use individual-level survey data from 1996 merged with the household-level survey data to capture the predominant religious/ethnic identity of the household. Each resident age 15 through 59 of the neighborhoods and households described above was interviewed. All interviews were conducted in Nepalese, the most common language in Nepal. The survey enjoyed a 97 percent response rate. The full analytic sample of households used in this paper is 1,651.

\section{MEASURES}

\section{Perceptions of Environmental Degradation}

We use four measures of perceptions of environmental degradation. Each is coded dichotomously, where 1 indicates a worse situation at the time of interview compared to three years ago, and 0 indicates a better situation or no change. Descriptive statistics for all measures used in these analyses are presented in Table 1.

Households that stall-feed their animals were asked: "Currently, how long does it take to travel to the place where the fodder is, collect it, and then bring it home?" They were then asked the same question in reference to three years ago, ${ }^{2}$ allowing us to construct a dichotomous measure of whether they perceive an increase in their fodder collection time over the three-year period. ${ }^{3}$ Although a number of changes might cause collection times to increase, we use reported travel time as a measure of perceived environmental degradation because it indicates that deforestation of nearby bushes and trees necessitates travel to more distant places to collect fodder. Overall, more than 75 percent of households stall-feed their animals (often in addition to grazing), and of those households, 7 percent perceived that the time they spent collecting fodder increased over the three-year period.

Households that used firewood as a source of fuel were asked a similar 
POPULATION AND ENVIRONMENT

TABLE 1

Means and Standard Deviations of Measures Used in Analyses

\begin{tabular}{|c|c|c|c|c|c|}
\hline & $\mathrm{N}$ & Mean & $\begin{array}{l}\text { Standard } \\
\text { Deviation }\end{array}$ & Minimum & Maximum \\
\hline \multicolumn{6}{|l|}{ Perceptions of Environmental } \\
\hline \multicolumn{6}{|l|}{ Degradation } \\
\hline Time to collect fodder increased & 1,149 & .07 & & 0 & 1 \\
\hline Time to collect fuel wood increased & 1,215 & .13 & & 0 & 1 \\
\hline Fertilizer requirement increased & 1,171 & .54 & & 0 & 1 \\
\hline Water table decreased & 1,651 & .30 & & 0 & 1 \\
\hline \multicolumn{6}{|l|}{ Neighborhood Social Change } \\
\hline $\begin{array}{l}\text { Number of new facilities within a } \\
15 \text {-minute walk (past three years) }\end{array}$ & 1,651 & .60 & .67 & -1 & 2 \\
\hline \multicolumn{6}{|l|}{ Household Characteristics } \\
\hline Number of household members & 1,651 & 5.56 & 2.50 & 1 & 26 \\
\hline Housing quality & 1,640 & 7.66 & 2.81 & 4 & 15 \\
\hline Household goods owned & 1,651 & 1.60 & 1.36 & 0 & 8 \\
\hline $\begin{array}{l}\text { Household owns any bari land (high } \\
\text { land) }\end{array}$ & 1,651 & .54 & & 0 & 1 \\
\hline $\begin{array}{l}\text { Household owns any khet land (low } \\
\text { land) }\end{array}$ & 1,651 & .57 & & 0 & 1 \\
\hline Household has toilet facility & 1,651 & .65 & & 0 & 1 \\
\hline \multicolumn{6}{|l|}{ Religious/ethnic group } \\
\hline Upper caste Hindu (reference) & 1,651 & .47 & & 0 & 1 \\
\hline Lower caste Hindu & 1,651 & .12 & & 0 & 1 \\
\hline Newar & 1,651 & .07 & & 0 & 1 \\
\hline Terai Tibeto-Burmese & 1,651 & .16 & & 0 & 1 \\
\hline Hill Tibeto-Burmese & 1,651 & .19 & & 0 & 1 \\
\hline \multicolumn{6}{|l|}{ Respondent Characteristics } \\
\hline Age & 1,651 & 41.45 & 14.17 & 15 & 85 \\
\hline Gender $($ Female $=1$ ) & 1,651 & .46 & & 0 & 1 \\
\hline
\end{tabular}

series of questions about time to collect firewood. We use this as a measure of a perception of environmental degradation because the destruction of nearby tree stands and forests necessitates travel to more distant places to collect firewood. Thirteen percent of households indicated that they spent more time collecting firewood at the time of the survey (1996) compared to three years prior.

Farming households that ever used fertilizer were asked whether more (or the same or less) chemical fertilizer would be required at the time of the interview to achieve the same crop production they had three years ago. More than half (54 percent) said they would have to apply more fertil- 
izer. Although fertilizer requirements may increase for a variety of reasons (such as lack of irrigation or inadequate manure), poor soil quality was one of the most common reasons cited by respondents for decreases in crop productivity when asked in an open-ended question about why they believed their crop production had decreased. We therefore use this question to measure the perception of environmental degradation in the form of poorer soil quality.

All respondents were also asked whether they thought the water table was lower at the time of the interview than it was three years ago. Nearly one-third (30 percent) believed that the water table had declined.

\section{Social Change}

Social change is measured in this analysis as the number of new facilities placed near the neighborhood over the past three years. These measures are constructed entirely from neighborhood history calendars, which identify the locations of the nearest facilities regardless of neighborhood boundaries. To identify households that are particularly close to these services, we use a relatively short distance threshold to measure proximity - a 15-minute walk. ${ }^{4}$ We expect that new facilities are most likely to affect residents' perceptions of environmental degradation when those residents are in direct, daily contact with the facility. Ten types of neighborhood facilities are included in the measure: schools, health centers, bus stops, wage employers, ${ }^{5}$ markets, banks, mills, agricultural co-operatives, dairies, and police stations. ${ }^{6}$ Our measure is constructed by subtracting the actual number of neighborhood facilities within a 15-minute walk three years prior to the household survey from the actual number of neighborhood facilities within a 15-minute walk at the time of the survey. Note that some neighborhoods actually lost facilities. For example, in one neighborhood a school closed and no new facilities were added, yielding a code of -1 on this measure.

\section{Household Characteristics}

We also include measures of household characteristics in the analyses to test for spurious correlations between neighborhood change and environmental degradation. If households with certain characteristics are more likely to be located in neighborhoods that gain new facilities and more likely to experience or perceive environmental degradation, then perceptions of degradation may actually be caused by household characteristics rather than neighborhood change (Pitt et al., 1999; Pitt et al., 1993). For example, neighborhoods with very poor households may be targeted for new facili- 
ties, and poor households may also be the most likely to report declines in environmental quality because they have greater reliance on common resources such as forest and grazing land, and because they have shallow wells.

Number of household members is coded from a census of all household residents conducted at the beginning of the household survey. Housing quality is a scale constructed from interviewer observations of the materials used for the floor, roof, walls, and the number of stories of the house. Floor type is coded 1 for mud or wood, 2 for concrete or brick. Roof material is coded 1 for thatch, 2 for stone/slate, 3 for tin, and 4 for concrete. Walls are coded 1 for mud or cane, 2 for wood shakes, 3 for stone/slate, and 4 for concrete or brick. Finally, the number of stories in the house is coded as the actual number. These four scores are summed to create the housing quality index, which ranges from 4 to 15 . Household goods owned is a count of multiple household possessions, including a radio, television, bicycle, motorbike, cart, tractor, pump set (for irrigation), and other farm tools. Land ownership is established using two dichotomous measures of whether the household owns any bari land (high land) and whether the household owns any khet land (low land, preferred for growing rice); 1 indicates ownership and 0 indicates no ownership. Finally each respondent was asked whether the household has a toilet facility (coded 1 for yes, 0 for no).

\section{Respondent Characteristics}

We also include measures of age and gender of the main respondent in the household survey and the main religious/ethnic group of the household to test whether these characteristics tend to be associated with measures of environmental degradation or neighborhood change, and thus result in spurious correlations between neighborhood change and environmental degradation. This may be the case, for example, if older respondents are more likely to perceive environmental degradation and are more likely to live in neighborhoods experiencing high levels of change. Or some ethnic groups may be more likely to live near new facilities (because governments tend to allocate such change to elite groups in society [Hart, Turton, \& White, 1989]) and may also be less likely to perceive environmental degradation.

Age and gender of the respondent were recorded in the household questionnaire. Age is coded in years; gender is coded 1 for woman and 0 for man. Religious/ethnic group was asked in an individual-level questionnaire administered to respondents between the ages of 15 and 59 in every household. These data are merged with the household questionnaire to indi- 
cate the predominant religious/ethnic group in the household. The vast majority of households consist of only one religious/ethnic group. In cases where individuals from multiple religious/ethnic groups comprise a household, the most common religious/ethnic group is used. This measure is coded as a series of five dichotomous variables: upper caste Hindu, lower caste Hindu, Newar, Hill Tibeto-Burmese, and Terai Tibeto-Burmese.

Upper caste Hindus are an elite group in Nepalese society who historically have had the most power and greatest opportunity (Acharya \& Bennet, 1981; Bennet, 1983). Lower caste Hindus have enjoyed fewer opportunities but identify with the same religious background-both groups' ancestors originate from India, and both groups practice Hinduism. Newars, a Tibetan-origin group who practice a mixture of Buddhism and Hinduism (Gellner \& Quigley, 1995), are also an elite group in Nepal with education levels that rival those of the upper caste Hindus (Gellner \& Quigley, 1995). Hill Tibeto-Burmese, who are also of Tibetan origin but tend to practice Buddhism, include groups such as Tamang, Gurung, and Magar (Gurung, 1980; Fricke, 1986; McFarlane, 1976). The last group, the Terai TibetoBurmese, are the original inhabitants of the Chitwan Valley (Guneratne, 1994). Including groups like Tharu and Derai, they are indigenous jungledwellers who were forced into sedentary agriculture in the 1950s when the valley was cleared and converted to farmland. These people have been much less able to take advantage of the social changes occurring around them than other groups. They are, on average, much less educated, have higher rates of infant mortality and other health problems, and own less land than the other ethnic groups (Guneratne, 1994).

\section{ANALYTIC STRATEGY}

We use logistic regression to estimate models of the relationship between the number of new neighborhood facilities and perceptions of environmental degradation. Logistic regression is appropriate because the dependent variables are dichotomous. We present the additive increase on the log-odds of the respondent reporting perceived environmental degradation.

\section{RESULTS}

Overall Relationship Between Neighborhood Change and Measures of Environmental Degradation

Panel A of Table 2 shows the bivariate relationships between neighborhood change and perceived environmental degradation. Three of the four 
POPULATION AND ENVIRONMENT

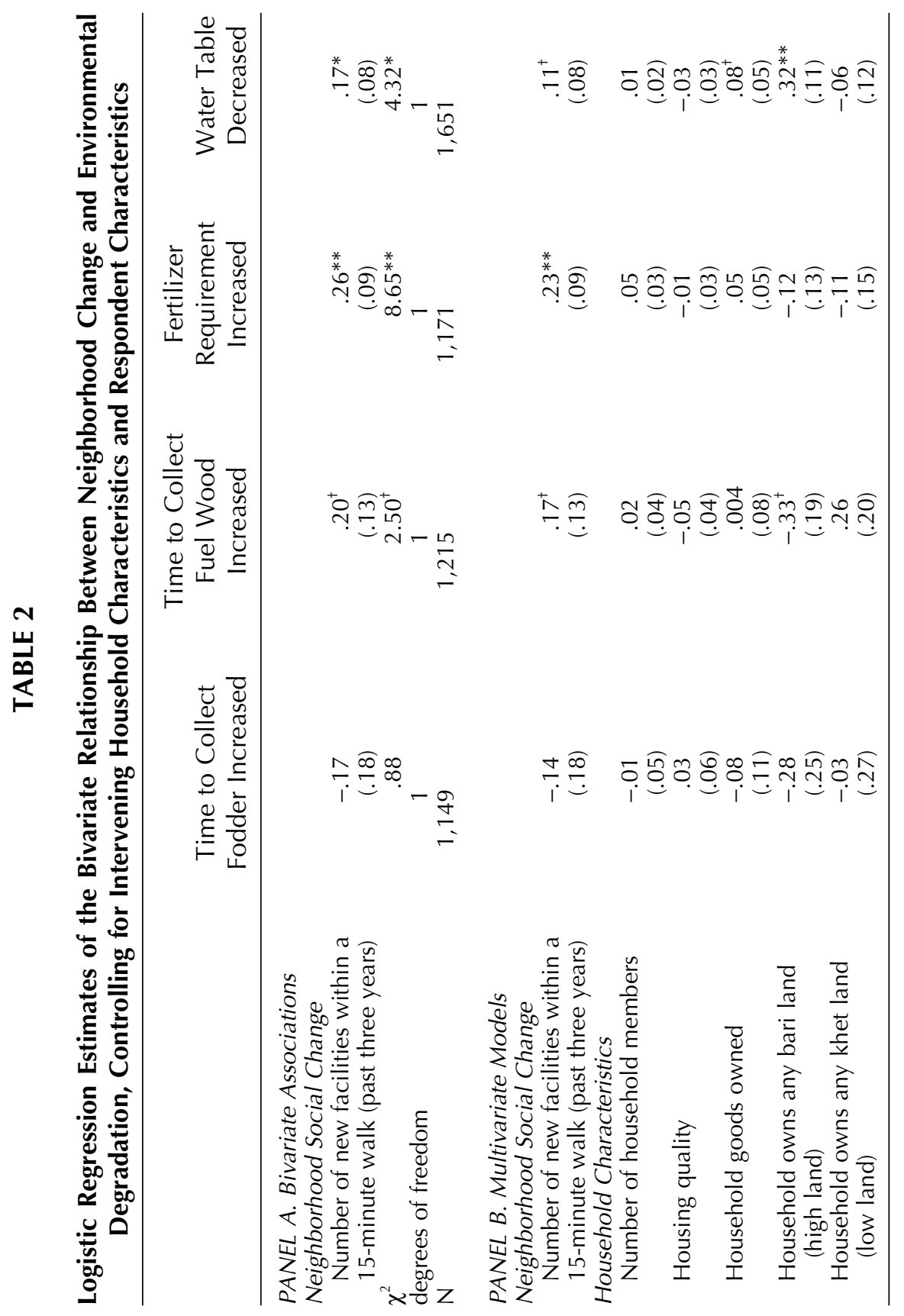




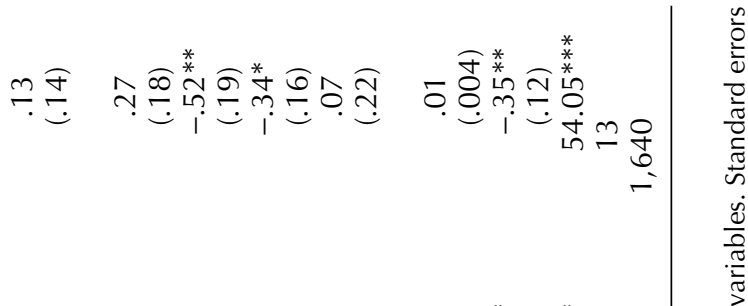

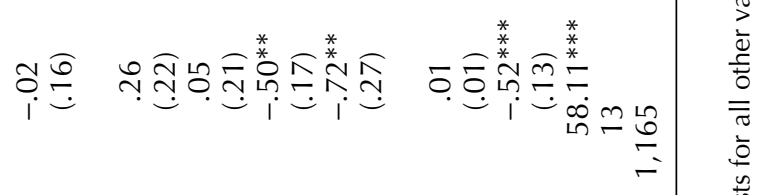

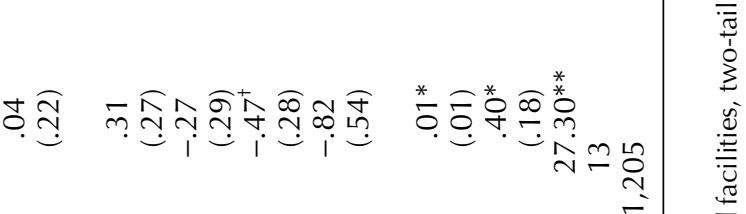

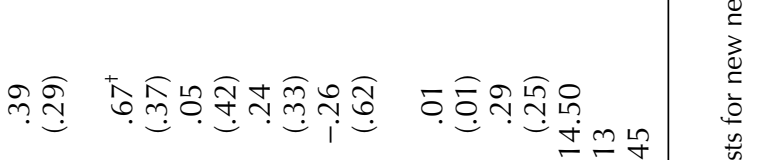

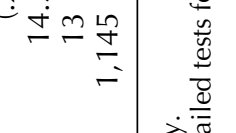

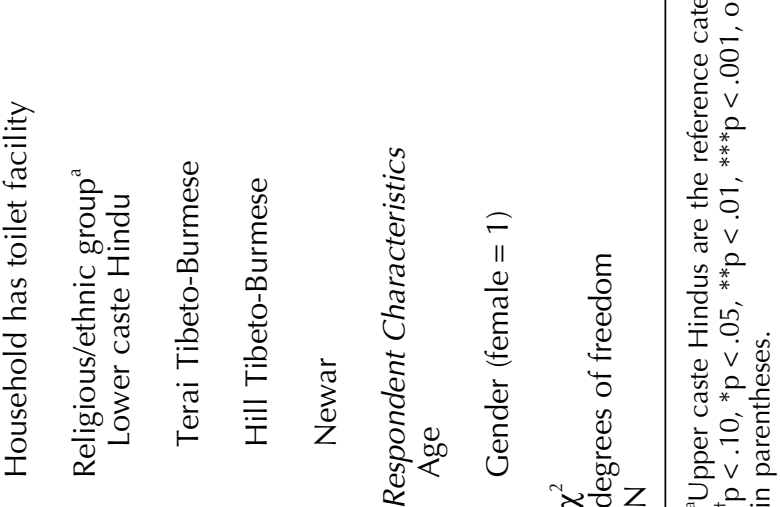


measures of environmental degradation-increased collection time for firewood, increased fertilizer requirements, and decreased water table levelare related to the number of new facilities in the neighborhood. Each new neighborhood facility increases the log-odds by .20 of perceiving an increase in the time to collect firewood. This translates into a 49 percent $\left(\mathrm{e}^{2 \times 20}=1.49\right)$ higher odds of reporting an increase in firewood collection time among households in neighborhoods with two new facilities than among households in neighborhoods that stayed the same. Similarly, households in neighborhoods that gained two new facilities in the previous three years have 68 percent higher odds of reporting increased fertilizer requirements and 40 percent higher odds of perceiving a lower water table. New neighborhood facilities, however, did not yield an increase in the reported time to collect fodder.

Overall, the models presented in Panel A of Table 2 show a strong relationship between neighborhood social change and perceived environmental degradation. This suggests that residents of neighborhoods that gain new facilities, while they may experience increases in quality of life in other important ways, perceive declines in the quality of their environment.

\section{Household and Individual Characteristics}

Panel B of Table 2 shows the extent to which these perceptions of changes in the environment may be due to household or respondent characteristics. Recall that the models in Table 2 may in some sense be "overcontrolled" and thus underestimate the true association between neighborhood change and perceived environmental quality. This is because household characteristics may be intervening mechanisms transmitting the influence of neighborhood change to environmental quality. For example, households in neighborhoods that gained public and private facilities are more likely to sell off portions of their land, which may lead them to overcrop their existing land and, in turn, use larger amounts chemical fertilizer to achieve the same crop productivity. In this case, increasing neighborhood facilities would be positively associated with more chemical fertilizer use, but this relationship would be underestimated by our model because we investigate the relationship only among households with similar land ownership (that is, we control for land ownership).

Indeed, the relationship between the number of new facilities and each perception of environmental degradation are smaller in Panel $B$ than in the corresponding bivariate model in Panel A. In other words, household and respondent characteristics explain part of the relationship between neighborhood change and perceived environmental degradation. 
Note also that multiple individual and household characteristics are related to perceptions of environmental quality. In general, for example, Terai Tibeto-Burmese, Hill Tibeto-Burmese, and Newar households are less likely than upper caste Hindus to perceive declines in environmental quality. Some characteristics, however, have mixed relationships to the measures of environmental degradation. For example, households that own bari (high) land are more likely than those that own khet (low) land to perceive a decrease in the water table, but less likely to perceive an increase in their time to collect fuel wood. This may be because bari land owners are more likely to use river or stream water (as opposed to well water), and thusgiven the seasonal fluctuations in river levels in this setting-may be less likely to detect overall decreases in the water table. In terms of wood availability, bari land tends to contain more shrubs and trees that can be used for firewood.

In addition, we find that the age and gender of household respondents are related to perceptions of environmental degradation. In particular, elderly respondents are more likely to perceive an increase in their collection time for fuel wood. ${ }^{7}$ And we find that women are much more likely to perceive an increase in fuel wood collection time (consistent with Agarwal's [1997] findings from South Asia) while men more likely to perceive an increase in fertilizer requirements. This is not surprising, given that women are usually responsible for collecting the fuel wood used for cooking and men tend to be responsible for purchasing chemical fertilizers.

However, we also find that many of these characteristics are unrelated to neighborhood change (not shown in tables) and thus do not mediate or explain much of the overall relationship between neighborhood change and perceived environmental quality. In the paragraphs below, we highlight characteristics that are related to increases in new neighborhood facilities and then provide details about the characteristics that explain part of the statistically significant relationships in Panel A.

\section{Growth in New Facilities}

Lower caste Hindu households are more likely to be in neighborhoods that have increases in the number of nearby facilities, while Hill TibetoBurmese households are less likely. Households with higher quality housing and fewer consumer goods are less likely to experience a growth in neighborhood facilities, perhaps because urban planners attempt to place new neighborhood facilities in less visibly wealthy neighborhoods. However, households with a toilet facility and that own land (khet or bari) are more likely to experience increases in the number of nearby neighborhood 
facilities, suggesting that households with land are better able to command the resources required to attract a new facility to their neighborhood. Neither age nor gender is associated with neighborhood change.

\section{Time to Collect Fuel Wood}

Individual and household characteristics explain approximately 15 per$\operatorname{cent}^{8}$ of the magnitude of the association between neighborhood change and increased time to collect fuel wood. This is because Hill Tibeto-Burmese households are simultaneously less likely to be in neighborhoods that gain new facilities and less likely to perceive an increase in fuel wood collection time. Although additional characteristics are related to a perceived increase in time (i.e., ownership of bari land, age, and gender), age and gender are not related to increases in neighborhood facilities, and the relationship between bari land ownership and gaining neighborhood facilities is in the wrong direction to explain the decrease in magnitude of the key coefficient between Panel A and Panel B.

\section{Fertilizer Requirements}

Household and respondent characteristics explain about 12 percent of the association between neighborhood change and increased fertilizer requirements. Again, this is due to Hill Tibeto-Burmese groups, who are simultaneously less likely to live in neighborhoods that gained new facilities and less likely to perceive that their fertilizer requirements increased. Other characteristics related to perceptions of fertilizer requirements are not related to the number of new facilities in a neighborhood, and thus cannot explain the change in effects between Panel A and Panel B. Overall, the relationship between neighborhood change and increasing fertilizer requirements remains strong and statistically significant, even when household characteristics are statistically controlled in the model.

\section{Water Table}

Household and individual characteristics explain approximately 35 percent of the association between new neighborhood facilities and the perception of a decreasing water table. Once again, this decrease in magnitude between the models in Panel A and Panel B is due to the Hill TibetoBurmese, who are less likely to gain new neighborhood facilities and also less likely to perceive that their water table has decreased. In this case, however, another characteristic accounts for part of the association: house- 
holds that own bari land are both more likely to gain new neighborhood facilities and more likely to perceive decreases in their water table.

\section{SUMMARY AND CONCLUSION}

Overall, these analyses indicate that increasing neighborhood facilities are associated with perceived environmental degradation-the depletion of common forest resources, increased chemical fertilizer requirements, and lower water tables. Some of these relationships are linked to household characteristics, such as religious/ethnic group membership. Recall that household characteristics, however, may be intervening mechanisms that explain the relationship between neighborhood social change and environmental degradation, and thus may not be appropriately thought of as statistical controls.

Measures used in these analyses are based on respondents' perceptions of environmental degradation. These perceptions are particularly interesting because, although they are more likely than actual degradation to influence behavior, they may be influenced by multiple factors in addition to actual degradation. In other words, particular groups of people may be more likely than others to report or perceive environmental degradation even though they experience the same environmental conditions. For instance, in this setting, both upper and lower castes Hindus seem particularly likely to perceive environmental degradation. This tendency is interesting in light of existing research suggesting that local elites are more likely to benefit from neighborhood facilities allocated by governments (Hart, Turton, \& White, 1989) — neighborhood facilities that our research suggests may be accompanied by environmental degradation. Further research will be required to discover whether this relationship is due to actual differences in environmental degradation, differences in religious/ethnic group perceptions of environmental quality, or differences in level of awareness of the local environment.

These and similar findings in this study highlight the larger need for research to better understand what shapes perceptions of the environment, as well as research that uses additional measures of environmental degradation and behaviors related to the environment. Direct, objective measures of local environmental degradation, such as plant biodiversity and abundance of common land, the depth of well water, or soil quality, will allow us to further understand the links between neighborhood change and environmental quality.

Assuming, however, that the relationship highlighted here-between new 
neighborhood facilities and perceived environmental degradation-is due at least in part to true environmental degradation, then new facilities are likely to have different consequences for different groups in society. Women and children (especially female children) may be least likely to benefit from new neighborhood facilities because they are least likely to be able to take advantage of those facilities, and may also be the most likely to suffer as a consequence of their accompanying environmental degradation. Women and children are mainly responsible for gathering firewood, fodder, and water; increases in the time required for these tasks will add to an often already overwhelming workday. Decreased crop production (if increasing fertilizer requirements cannot be met) are likely to affect women and children the most as well, because the household allocation of food and other resources often favors men. In addition, landless and other economically marginalized peoples who also may realize fewer benefits from new facilities will suffer more than their richer neighbors if common lands and other common resources are lost or degraded. Because their private resources are so much less adequate, they are forced to rely more heavily on common resources. As these common resources shrink and become less valuable, their richer neighbors shift their own resource use to private resources; however, those without private resources are forced to go without.

Although previous research has highlighted the numerous positive consequences of new health centers, schools, employment opportunities, and transportation infrastructure, these findings suggest that new facilities may induce hardships by degrading natural resources, and that these hardships may disproportionately impact women, children, and the economically less fortunate. New facilities clearly increase perceptions of environmental degradation. However, new facilities are also are linked to decreases in fertility, which may act to reduce strain on environmental resources. In general, we conclude that environmental consequences should be considered when deciding where to place new local facilities. Our focus in this study is on an agricultural setting bordering a rich ecological reserve. Consideration of the environmental consequences of the expansion of new facilities may be particularly important in such settings.

Finally, the results presented here illuminate approaches to conceptualization of the determinants of environmental quality at the very local level. Our findings indicate that changes in the proliferation of neighborhood facilities may have a significant influence on local environmental quality. This finding is not only important for the construction of more comprehensive models of environmental quality, it may also reshape the way we think about other determinants of environmental quality. For example, a number of scholars have argued that changes in population processes 
such as fertility or migration have an important influence on the environment (Bilsborrow \& DeLargy, 1991; Bongaarts, 1996; Cohen, 1995; Eckholm, 1976; Ehrlich, Ehrlich \& Daily, 1993; Heilig, 1997; Myers, 1991; Rees, 1996). We know from recent research that changes in community characteristics have dramatic influences on both fertility and migration (Axinn \& Barber, 2001; Axinn \& Yabiku, 2001; Entwisle, Casterline, \& Sayed, 1989; Massey \& Espinoza, 1997). Given these results demonstrating significant effects of community change on perceptions of environmental degradation, it is quite possible that changes in neighborhood facilities are responsible for changes in both population parameters and environmental degradation. If so, the observed effects of some determinants of environmental quality, such as population change, may actually be a product of other neighborhood-level changes. Thus, investigation of the role of neighborhood change in shaping other local determinants of environmental degradation should be a high priority in research aimed at understanding environmental degradation.

\section{ACKNOWLEDGMENT}

This research was supported by two grants from NICHD (R01HD31982 and R01-HD33551). We would like to thank Dirgha Ghimire for comments, the Population and Ecology Research Laboratory in Nepal for collecting these data, and Paul Schulz and Heather Gatny for research assistance.

\section{ENDNOTES}

1. The population density of the U.S. is 79.6 people per square mile, ranging from 1.1 in Alaska and 5.1 in Wyoming to 1,003 in Rhode Island and 1,134 in New Jersey. For example, the Dallas-Forth Worth metropolitan area has 573.6 people per square mile (U.S. Census Bureau, 2000).

2. Of course, it is possible that farmers are not able to recall accurately how long it took to collect fodder three years ago. However, because this question was asked soon after the question about current time to collect fodder, we believe it represents a reasonable measure of the comparison between time to collect fodder three years ago and now. Even this comparison, however, may not represent the actual change in time to collect fodder. As we describe above, however, we are particularly interested in respondents' perceptions of environmental degradation for three reasons: (1) objective measures of these types of environmental degradation are not available in these data or for this study area; (2) perceptions are essential to sustainable programs and policies aimed at improving environmental conditions; and (3) perceptions are likely to influence individual behavior.

3. We also constructed a continuous measure of the perceived change in number of minutes 


\section{POPULATION AND ENVIRONMENT}

to collect fodder. Regardless of whether we use a continuous or dichotomous measure of perceived increase in time to collect fodder, our analytic results remain the same. In addition, because the other perceptions are dichotomous, we present the simpler, dichotomous measure in Table 2.

4. We also re-estimated these models using many different thresholds. Varying the distance threshold produces virtually no substantive changes in the interpretation of our results.

5. We allowed neighborhood residents to define "employer". Through multiple interviews in multiple neighborhoods, a consensus emerged that an employer who employed 10 or more individuals for a regular wage constituted a significant neighborhood resource.

6. We constructed this measure two additional ways, based on the results of a factor analysis. We first removed the two items that correlate negatively with the scale: banks and police stations. Second, we removed two more items that have relatively small correlations with the overall scale: schools and bus service. Models including these scales led to estimates extremely similar to those presented in Table 2 .

7. This may be because elderly respondents were more likely to include longer periods of retrospection in their reference frame, in spite of the instruction to think only about the past three years.

8. This is computed by comparing the original log-odds coefficient with the new/revised logodds coefficient. The panel A coefficient was .20, and the panel B coefficient is .17. Thus, $(.20-.17) / .20=.15$, or $15 \%$.

\section{REFERENCES}

Acharya, M., \& Bennett, L. (1981). The Status of Women in Nepal: The Rural Women of Nepal. Kathmandu: Tribhuvan University.

Agarwal, B. (1992). The gender and environment debate: Lessons from India. Feminist Studies, 18(1), 119-158.

Agarwal, B. (1997). Gender, environment, and poverty interlinks: Regional variations and temporal shifts in rural India, 1971-91. World Development, 25(1), 23-52.

Axinn, N. W., \& Axinn, G. H. (1983). Small farmers in Nepal: A farming systems approach to description. Kathmandu, Nepal: Rural Life Associates.

Axinn, W. G., \& Barber, J. S. (2001). Mass education and fertility limitation. American Sociological Review, 66, 481-505.

Axinn, W. G., Barber, J. S., \& Biddlecom, A. E. (2000). Social change, family size, and environmental consumption. Paper presented at the annual meetings of the Population Association of America, San Francisco, March 23-25.

Axinn, W. G., Barber, J. S., \& Ghimire, D. J. (1997). The neighborhood history calendar: A data collection method designed for dynamic multilevel modeling. Sociological Methodology, 27, 355-92.

Axinn, W. G., \& Yabiku, S. T. (2001). Social change, the social organization of families, and fertility limitation. American Journal of Sociology, 106, 1219-1261.

Barber, J. S. (in press). Communities and attitudes: The influence of nonfamily institutions and experiences on dispositions toward marriage. Social Psychology Quarterly.

Barber, J. S., Pearce, L. D., Chaudhury, I., \& Gurung, S. (2002). Voluntary associations and fertility limitation. Social Forces, 80(4), 1369-1401.

Baydar, N., White, M. J., Simkins, C., \& Babakol, O. (1990). Effects of agricultural development policies on migration in peninsular Malaysia. Demography, 27(1), 97-109.

Bennet, L. (1983). Dangerous Wives and Sacred Sisters. New York: Columbia University Press.

Bilsborrow, R. F., \& DeLargy, P. F. (1990). Land use, migration, and natural resource deterioration: The experience of Guatemala and the Sudan. In K. Davis \& M. Bernstam (Eds.), Resources, Environment, and Population (pp. 125-147). Oxford: Oxford University Press. 
Bongaarts, J. (1996). Population pressure and the food supply system in the developing world. Population and Development Review, 22(3), 483-503.

Brooks-Gunn, J., Duncan, Greg J., Klebanov, P. K., \& Sealand, N. (1993). Do neighborhoods influence child and adolescent development? American Journal of Sociology, 99, 353395.

Chaudhary, R. P. (1998). Biodiversity in Nepal: Status and conservation. Saharanpur, Uttar Pradesh, India: S. Devi.

Cohen, J. (1995). How many people can the Earth support? New York: Norton.

Dang, A., Goldstein, S., \& McNally, J. (1997). Internal migration and development in Vietnam. International Migration Review, 31(2), 312-337.

Daniere, A. G., \& Takahashi, L. M. (1999). Environmental behavior in Bangkok, Thailand: A portrait of attitudes, values, and behaviors. Economic Development and Cultural Change, $47(3), 525-557$.

Eckholm, E. (1976). Losing ground: Environmental stress and world food prospects. New York: Norton.

Ehrlich, P., Ehrlich, A., \& Daily, G. (1993). Food security, population, and environment. Population and Development Review, 19(1), 1-32.

Entwisle, B., Casterline, J.B., \& Sayed, H.A. (1989). Villages as contexts for contraceptive behavior in rural Egypt. American Sociological Review, 54, 1019-1034.

Entwisle, B., \& Mason W. (1985). Multilevel affects of socioeconomic development and family planning programs on children ever born. American Journal of Sociology, 91, 616-649.

Foster, J. B. (1999). Marx's theory of metabolic rift: Classical foundations for environmental sociology. American Journal of Sociology, 105, 366-405

Fricke, Tom. (1986). Himalayan households: Tamang demography and domestic processes. Ann Arbor: UMI Research Press.

Gellner, D. N., \& Quigley, D. (Eds). (1995). Contested hieararchies: A collaborative ethnography of caste among the Newars of the Kathmandu Valley, Nepal. New York: Oxford University Press.

Guneratne, U. A. (1994). The Tharus of Chitwan: Ethnicity, class and the state in Nepal. Unpublished dissertation. University of Chicago.

Gurung, S. B. (1998). The land and the people. In P. Shumshere, J. B. Rana, \& D. N. Dhungel (Eds.), Contemporary Nepal (pp. 1-13). New Delhi: Vikas Publishing House Pvt. Ltd.

Hart, G., Turton, A., \& White, B., with Fegan, B., \& Ghee, L.T. (Eds.). (1989). Agrarian transformations: Local processes and the state in southeast Asia. Berkeley: University of California Press.

Heilig, G. K. (1997). Anthropogenic factors in land-use change in China. Population and Development Review, 23(1), 139-168.

Huber, J. (Ed.). (1991). Macro-Micro linkages in sociology. Newbury Park, CA: Sage.

Joshi, N. N., Jali, N. M., \& Hamid, A.H. (1997). Organized structure, performance, and participation: Forest user groups in the Nepal hills. In G. Shivakoti, G. Varughese, E. Ostrom A. Shukla, \& G. Thapa (Eds.), People and participation in sustainable development: Understanding the dynamics of natural resource systems (pp. 55-63). Bloomington, IN: Indiana University.

Martin, P. (1992). Migration and development. International Migration Review, 26(3), 10001012.

Marx, K. ([1867] 1976). Capital: A critique of political economy, (Vol. 1). New York: Vintage.

Marx, K. ([1863-65] 1981). Capital: A critique of political economy, (Vol. 3). New York: Vintage.

Massey, D. S., \& Espinoza, K. E. (1997). What's driving Mexico-U.S. migration? A theoretical empirical, and policy analysis. American Journal of Sociology, 102, 939-999.

Myers, N. (1988). Threatened biotas: "Hot spots" in tropical forests. Environmentalist, 8, 187208.

Myers, N. (1991). The world's forests and human populations: The environmental interconnections. In K. Davis \& M. Bernstam (Eds.), Resources, environment, and population (pp. 237-251). Oxford: Oxford University Press. 


\section{POPULATION AND ENVIRONMENT}

National Research Council. (1993). Population and land use in developing countries. Washington, DC: National Academy Press.

Ogburn, W. F., \& Nimkoff, M.F. ([1955] 1976). Technology and the changing family. Westport, CT: Greenwood Press.

Pitt, M. M., Khandker, S.R., McKernan, S., \& Latif, M.A. (1999). Credit programs for the poor and reproductive behavior in low-income countries: Are the reported causal relationships the result of heterogeneity bias? Demography, 36, 1-21.

Pitt, M. M., Rosenzweig, M.R., \& Gibbons, D. M. (1993). The determinants and consequences of the placement of government programs in Indonesia. World Bank Economic Review, 7, 319-348.

Pokharel, B. N., \& Shivakoti, G.P. (1986). Impact of development efforts on agricultural wage labor. Winrock Rural Poverty Research Paper Series, No. 1.

Raudenbush, S. W. (1988). Educational applications of hierarchical linear models: A review. Journal of Educational Statistics, 13, 85-116.

Rees, W. (1996). Revisiting carrying capacity: Area-based indicators of sustainability. Population and Environment, 17(3), 195-215.

Rountree, P. W., Land, K. C., \& Miethe, T.D. (1994). Macro-micro integration in the study of victimization: A hierarchical logistic model analysis across Seattle neighborhoods. Criminology, 32, 387-413.

Shivakoti, G. P., Axinn, W.G., Bhandari, P., \& Chhetri, N. (1999). The impact of community context on land use in an agricultural society. Population and Environment, 20(3), 191213.

Shivakoti, G. P., \& Pokharel, B.N. (1989). Marketing of major crops in Chitwan: A case study of six village panchayats. Winrock Research Paper Series No. 8.

Shukla, A. K., Shivakoti, G., Benjamin, P., \& Ostrom, E. (1997). Reflections on irrigation policies in Nepal. In G. Shivakoti, G. Varughese, E. Ostrom, A. Shukla, \& G. Thapa (Eds.), People and participation in sustainable development: Understanding the dynamics of natural resource systems (pp. 276-289). Bloomington, IN: Indiana University.

Thapa, G. (1997). Indigenous management of Nepal's natural resources: Some policy issues. In G. Shivakoti, G. Varughese, E. Ostrom, A. Shukla, \& G. Thapa (Eds.), People and participation in sustainable development: Understanding the dynamics of natural resource systems (pp. 290-298). Bloomington, IN: Indiana University.

Thornton, A., \& Fricke, T.E. (1987). Social change and the family: Comparative perspectives from the West, China, and South Asia. Sociological Forum, 2(4), 746-772.

Thornton, A., \& Lin, H. (1994). Social change and the family in Taiwan. Chicago: University of Chicago Press.

United Nations. (1995). The world's women 1995: Trends and statistics. New York: United Nations.

United Nations. (2000). The world's women 2000: Trends and statistics. New York: United Nations.

U.S. Census Bureau. (2000). Census 2000 redistricting data (PL 94-171) summary file. American Factfinder at factfinder.census.gov.

Zajonc, R. B. (1968). The attitudinal effects of mere exposure. Journal of Personality and Social Psychology, 9 (monograph supplement no. 2), Page 2, 1-27.

Zurick, D., \& Karan, P. P. (1999). Himalaya: Life on the edge of the world. Baltimore, MD: Johns Hopkins. 